\title{
It Is Time to Modify Treatment to Enable More Women with Rheumatoid Arthritis to Have Successful Pregnancies
}

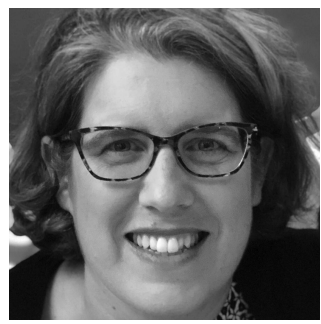

I met Linda, a 39-year-old woman diagnosed with severe rheumatoid arthritis (RA) in her mid-20s, in clinic a few months ago. Her condition had been well controlled with etanercept and methotrexate (MTX) for the past decade. Linda had been told at some point that she could not continue her medications during pregnancy. She was worried that her RA would worsen significantly while not taking her medications, so she had decided not to become a mother. Now that she was about to get married, she thought she should ask just one more time.

In this issue of The Journal, the metaanalysis by Jethwa, et al accurately describes the history of RA in pregnancy ${ }^{1}$. As early as the 1930s, the medical literature included reports of temporary improvements in RA during pregnancy, followed by a postpartum flare. It was this phenomenon that led Philip Hench to look for a "Substance X" that improved RA, ultimately contributing to the discovery of cortisol and the Nobel Prize in $1950^{2}$ (see box).

While studies suggested that surging cortisol in pregnancy might not be the mitigating factor for RA, other immunologic reasons have been discovered. In 1993, Nelson, et al published a study of 46 pregnant women with RA, demonstrating that the 34 who improved had a greater degree of maternal-fetal genetic disparity than the 12 who did not improve $^{3}$. Similarly, high levels of fetal DNA in the mother's circulation have been associated with decreased RA activity in pregnancy ${ }^{4}$. Both studies suggest that as the pregnant woman's immune system tolerizes to fetal antigens, she also tolerizes to herself, resulting in diminished autoimmunity during pregnancy. As the fetal DNA levels fall postpartum, so does this self-tolerance, and RA activity increases.

Retrospective studies between 1938 and the 1980s suggested dramatic improvements (remission in up to $75 \%$ of women during pregnancy) followed by flares in about $80 \%$. During this period, the large majority of women received no specific RA therapy during pregnancy other than, perhaps, prednisone. More modern prospective data, however, has suggested somewhat less dramatic change. As the metaanalysis reported by Jethwa, et al in this journal demonstrates, among prospective serially collected pregnancies, in $60 \%$ RA declines and in $47 \%$ there is a flare postpartum ${ }^{1}$. Interestingly, in studies reported between 1983 and 2005, $77 \%$ of patients with RA improved during pregnancy, compared with $55.3 \%$ among studies reported from 2008 to 2016. While the medication use in these cohorts was generally not well reported, only De Man, et al and Forger, et al included women taking disease-modifying antirheumatic drugs (DMARD), primarily hydroxychloroquine (HCQ) and/or sulfasalazine (SSZ) ${ }^{6,7}$. None of the women in the included cohorts used tumor necrosis factor (TNF) inhibitors during pregnancy. It is very likely that improvement in the baseline RA activity prior to pregnancy due to DMARD use mitigated improvements in pregnancy, because a woman with mild RA has little room for improvement during pregnancy.

This metaanalysis does not tell us about the future of RA and pregnancy. Fortunately, much about the management of RA has changed in the last 2 decades. With national guidelines encouraging a treat-to-target approach, many young women are now managed with DMARD and biologics, improving their daily functioning and preventing longterm disability. With these improvements, more young women with RA are interested in becoming mothers, but they are faced with the dilemma of balancing the safety of their medications for their offspring and the ramifications of stopping these medications for themselves.

The Jethwa metaanalysis could be interpreted as encouraging, suggesting that $60 \%$ of women with RA will improve in pregnancy ${ }^{1}$. I think that this interpretation might not be accurate, however, because the prepregnancy medications of the women in these studies do not match the current regimens of many of our patients. A woman well-controlled with biologic therapy should not expect to have a $60 \%$ chance of further improvement if she stops her effective therapy. Instead, she is likely to experience flare when the drug is stopped before conception. The Rhekiss Registry, a

See RA and pregnancy, page 245

Personal non-commercial use only. The Journal of Rheumatology Copyright @ 2019 . All rights reserved. 
national German rheumatic disease pregnancy registry, demonstrated that women who stop an anti-TNF medication for pregnancy have a 10-fold higher risk of RA flare than women not taking these medications prior to conception ${ }^{8}$.

It is also worth considering what happens to the $40 \%$ of women in this metaanalysis who do not improve. Recent data suggest that women with active RA during pregnancy have earlier deliveries, placing their offspring at risk for short-term and longterm complications. An analysis of the first 80 pregnancies in women with RA in my Duke Autoimmunity in Pregnancy Registry demonstrated that higher self-reported disability and physician-rated RA activity was associated with higher rates of preterm birth ${ }^{9}$. In the PARA study, higher levels of RA activity were associated with small for gestational age infants, and prednisone use was associated with preterm birth ${ }^{6}$.

There is growing evidence about the safety of antirheumatic medications in pregnancy and breastfeeding. Several rheumatology organizations have published guidelines for medication use in pregnancy, including the European League Against Rheumatism, the British Society of Rheumatology, and the Mexican College of Rheumatology $10,11,12,13$. The American College of Rheumatology (ACR) is currently writing guidelines to be presented during the 2018 ACR Scientific Meeting.

As these guidelines demonstrate, there are multiple medications that are considered compatible with pregnancy (Table 1). In my experience as a clinician, I can control almost all women's RA adequately with some combination of these.
I suggest that we revise our approach to pregnancy management for women with RA in these ways:

1. Ask your patient with RA if she would like to have a child (you might be surprised by the answer). Be open and optimistic as you help her adjust her medications to achieve a safe pregnancy.

2. Switch her RA therapy to include only pregnancy-compatible medications (Table 1). Instead of stopping MTX or other noncompatible medication and allowing a flare, switch her to SSZ, HCQ, or a TNF inhibitor she has not taken before or did well on before.

3. Have her continue her pregnancy-compatible medications when pregnant. I would allow her to pull back on her RA medications if tolerated - perhaps spreading out her anti-TNF injections or decreasing her daily dose of SSZ . My rule is that she needs to take enough of these medications to avoid a prednisone taper. I have found that almost all my patients are able to successfully follow this advice and maintain low levels of RA activity throughout pregnancy.

4. For women taking IgG-based TNF inhibitors, stop these drugs at around 32 weeks of gestation to avoid a high level of transfer to the fetus and potential immunosuppression at birth. Recommendations for when to hold these TNF inhibitors is debated, but I generally allow them until the third trimester because they do not appear to cause significant immunosuppression in infants; this practice is also endorsed by gastroenterologists ${ }^{14}$.

5. To avoid a postpartum flare, restart prepregnancy medications within 2 weeks of delivery. All RA medications

Table 1. Compatibility of antirheumatic medications with pregnancy, as listed in the EULAR Points to Consider and BSR guidelines.

\begin{tabular}{|c|c|c|}
\hline & EULAR & BSR \\
\hline \multicolumn{3}{|c|}{ Medications compatible with pregnancy } \\
\hline Hydroxychloroquine & Compatible with pregnancy & Compatible with pregnancy \\
\hline Azathioprine & Compatible with pregnancy & Compatible with pregnancy \\
\hline \multicolumn{3}{|l|}{ TNF inhibitors } \\
\hline Certolizumab & Consider throughout pregnancy & Compatible with pregnancy \\
\hline Adalimumab & Consider during the first trimester & Compatible with pregnancy; stop at 16 weeks \\
\hline Infliximab & Consider during the first trimester & $\begin{array}{l}\text { Compatible with pregnancy; stop at end } \\
\text { of second trimester }\end{array}$ \\
\hline Golimumab & Consider during the first trimester & No data \\
\hline Prednisone & Use in pregnancy if needed to control active disease & Compatible with pregnancy \\
\hline NSAID & $\begin{array}{l}\text { Use in pregnancy if needed to control active disease in } \\
\text { first and second trimesters }\end{array}$ & $\begin{array}{l}\text { Compatible with pregnancy; caution in first } \\
\text { trimester; none past } 32 \text { weeks of gestation }\end{array}$ \\
\hline Tofacitinib & Insufficient documentation; avoid until further evidence is available & - \\
\hline COX-2 inhibitors & Insufficient documentation; avoid until further evidence is available & Not compatible with pregnancy \\
\hline Other biologics & Limited documentation; replace before conception & Not compatible with pregnancy \\
\hline
\end{tabular}

EULAR: European League Against Rheumatism; BSR: British Society of Rheumatology; TNF: tumor necrosis factor; NSAID: nonsteroidal antiinflammatory drugs; COX-2: cyclooxygenase inhibitors.

Personal non-commercial use only. The Journal of Rheumatology Copyright @ 2019. All rights reserved 
that are compatible with pregnancy are compatible with breastfeeding.

a. If a woman has stopped her anti-TNF drug in the final months of pregnancy, then she restarts it within 1-2 weeks after delivery (the delay is to allow wound healing from delivery).

b. Nonsteroidal antiinflammatory drugs (especially ibuprofen) and prednisone are compatible with breastfeeding and can be used postpartum for pain and flares without harm to the infant.

6. Talk about contraception and when the patient wants to conceive again as you make medication changes.

Based on this approach to treatment, I told Linda that I did not see any reason she could not safely have a pregnancy and control her RA. She cried with joy.

More than half of all women diagnosed with RA before having children will have fewer children than they would otherwise choose. Limiting family size, and especially not having children at all, can dramatically decrease a woman's quality of life and happiness ${ }^{15}$. Women with RA report several reasons for their smaller-than-expected families: difficulty with conception, worries about their ability to care for a child, concerns about their medications, and fear of a postpartum flare. Each of these issues can be mitigated with careful management.

As our management of RA has advanced to allow a dramatically improved prognosis for our patients with RA, so must our pregnancy management. The old model of stopping all medications, crossing your fingers, and dosing prednisone as needed has resulted in many healthy babies, but also too many worried, pained, and childless women. With the documented safety of multiple effective medications in pregnancy, the management of RA during pregnancy can now evolve. Moving forward, I hope that this leads to fewer 39-year-old women almost missing the opportunity for motherhood and increases the ability of young women with RA to live the lives they want.

\section{MEGAN E.B. CLOWSE, MD, MPH,}

Department of Medicine,

Division of Rheumatology and Immunology, Duke University,

Durham, North Carolina, USA

Address correspondence to Dr. M.E. Clowse, Box 3535, Trent Drive, Durham, North Carolina 27710, USA. E-mail: Megan.clowse@duke.edu Dr. Clowse is a consultant for UCB.

\section{REFERENCES}

1. Jethwa H, Lam S, Smith C, Giles I. Does rheumatoid arthritis really improve during pregnancy? A systematic review and metaanalysis. J Rheumatol 2019;46:245-50.

2. Burns CM. The history of cortisone discovery and development. Rheum Dis Clin North Am 2016;42:1-14, vii.

3. Nelson JL, Hughes KA, Smith AG, Nisperos BB, Branchaud AM, Hansen JA. Maternal-fetal disparity in HLA class II alloantigens and the pregnancy-induced amelioration of rheumatoid arthritis N Engl J Med 1993;329:466-71.

4. Yan Z, Lambert NC, Ostensen M, Adams KM, Guthrie KA, Nelson JL. Prospective study of fetal DNA in serum and disease activity during pregnancy in women with inflammatory arthritis. Arthritis Rheum 2006;54:2069-73.

5. Da Silva JA, Spector TD. The role of pregnancy in the course and aetiology of rheumatoid arthritis. Clin Rheumatol 1992;11:189-94.

6. de Man YA, Dolhain RJ, van de Geijn FE, Willemsen SP, Hazes JM. Disease activity of rheumatoid arthritis during pregnancy: Results from a nationwide prospective study. Arthritis Rheum 2008;59:1241-8.

7. Forger F, Vallbracht I, Helmke K, Villiger PM, Ostensen M. Pregnancy mediated improvement of rheumatoid arthritis. Swiss Med Wkly 2012;142:w13644.

8. Fischer-Betz R, Sander O, Specker C, Brinks R, Schneider M. High risk of flares during pregnancy in women with rheumatoid arthritis who discontinue treatment with TNF inhibitors at conception [abstract]. Arthritis Rheumatol 2015;67 Suppl 10:2522.

9. Harris N, Eudy A, Clowse M. Patient-reported disease activity and adverse pregnancy outcomes in systemic lupus erythematosus and rheumatoid arthritis. Arthritis Care Res 2018 Jun 15 (E-pub ahead of print).

10. Gotestam Skorpen C, Hoeltzenbein M, Tincani A, Fischer-Betz R, Elefant E, Chambers C, et al. The EULAR points to consider for use of antirheumatic drugs before pregnancy, and during pregnancy and lactation. Ann Rheum Dis 2016;75:795-810.

11. Flint J, Panchal S, Hurrell A, van de Venne M, Gayed M, Schreiber $\mathrm{K}$, et al. BSR and BHPR guideline on prescribing drugs in pregnancy and breastfeeding-part II: analgesics and other drugs used in rheumatology practice. Rheumatology 2016;55:1698-702.

12. Flint J, Panchal S, Hurrell A, van de Venne M, Gayed M, Schreiber $\mathrm{K}$, et al. BSR and BHPR guideline on prescribing drugs in pregnancy and breastfeeding-part I: standard and biologic disease modifying anti-rheumatic drugs and corticosteroids. Rheumatology 2016;55:1693-7.

13. Saavedra Salinas MA, Barrera Cruz A, Cabral Castañeda AR, Jara Quezada LJ, Arce-Salinas CA, Álvarez Nemegyei J, et al. Clinical practice guidelines for the management of pregnancy in women with autoimmune rheumatic diseases of the Mexican College of Rheumatology. Part II. Reumatol Clin (English edition) 2015;11:305-15.

14. Nguyen GC, Seow CH, Maxwell C, Huang V, Leung Y, Jones J, et al. The Toronto consensus statements for the management of inflammatory bowel disease in pregnancy. Gastroenterology 2016;150:734-57 e1.

15. Canada AL, Schover LR. The psychosocial impact of interrupted childbearing in long-term female cancer survivors. Psychooncology 2012;21:134-43.

J Rheumatol 2019;46:223-5; doi:10.3899/jrheum.181036
"At the Mayo Clinic we saw, not infrequently, patients who had become pregnant during the course of their rheumatoid arthritis. It was observed that most of them noted, not long after the onset of pregnancy, an undramatic and slowly progressive development of relief from their arthritic disability."

Philip Hench, MD. Nobel Lecture,

December 1950

Personal non-commercial use only. The Journal of Rheumatology Copyright (C) 2019. All rights reserved. 